
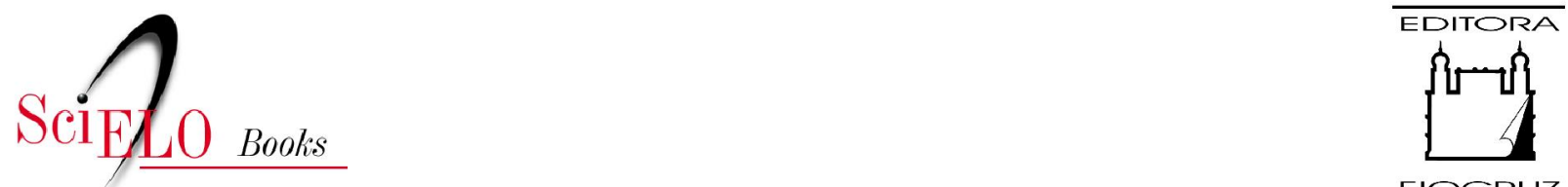

FIOCRUZ

\title{
Retrato de Paulo Carneiro
}

\author{
Marcos Chor Maio (org.)
}

MAIO, M. C. org. Retrato de Paulo Carneiro. In: Ciência, politica e relações internacionais: ensaios sobre Paulo Carneiro [online]. Rio de Janeiro: Editora FIOCRUZ; Unesco, 2004, pp. 325-339. ISBN: 978-85-7541-509-2. Available from: doi: 10.7476/9788575415092.0014. Also available in ePUB from: http://books.scielo.org/id/fczgd/epub/maio-9788575415092.epub.

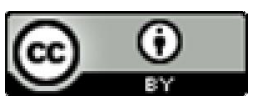

All the contents of this work, except where otherwise noted, is licensed under a Creative Commons Attribution $\underline{4.0 \text { International license. }}$

Todo o conteúdo deste trabalho, exceto quando houver ressalva, é publicado sob a licença Creative Commons Atribição 4.0.

Todo el contenido de esta obra, excepto donde se indique lo contrario, está bajo licencia de la licencia Creative Commons Reconocimento 4.0. 


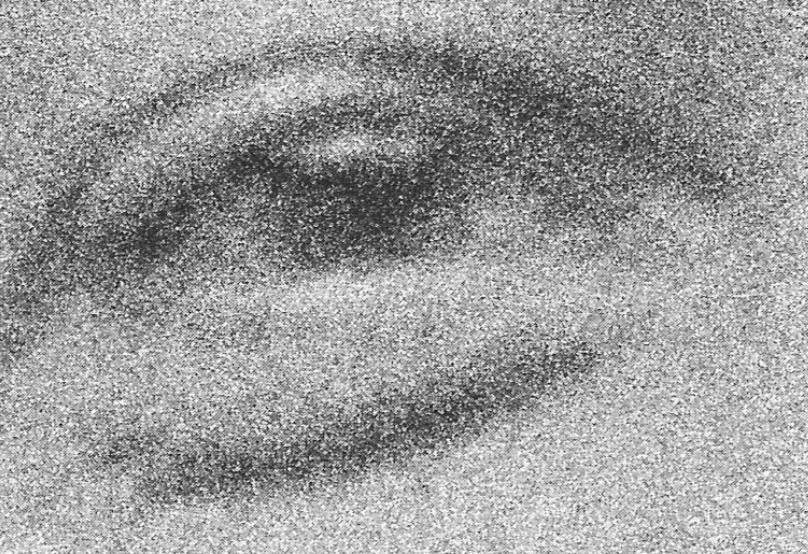

\section{Retrato de Paulo Carneiro}



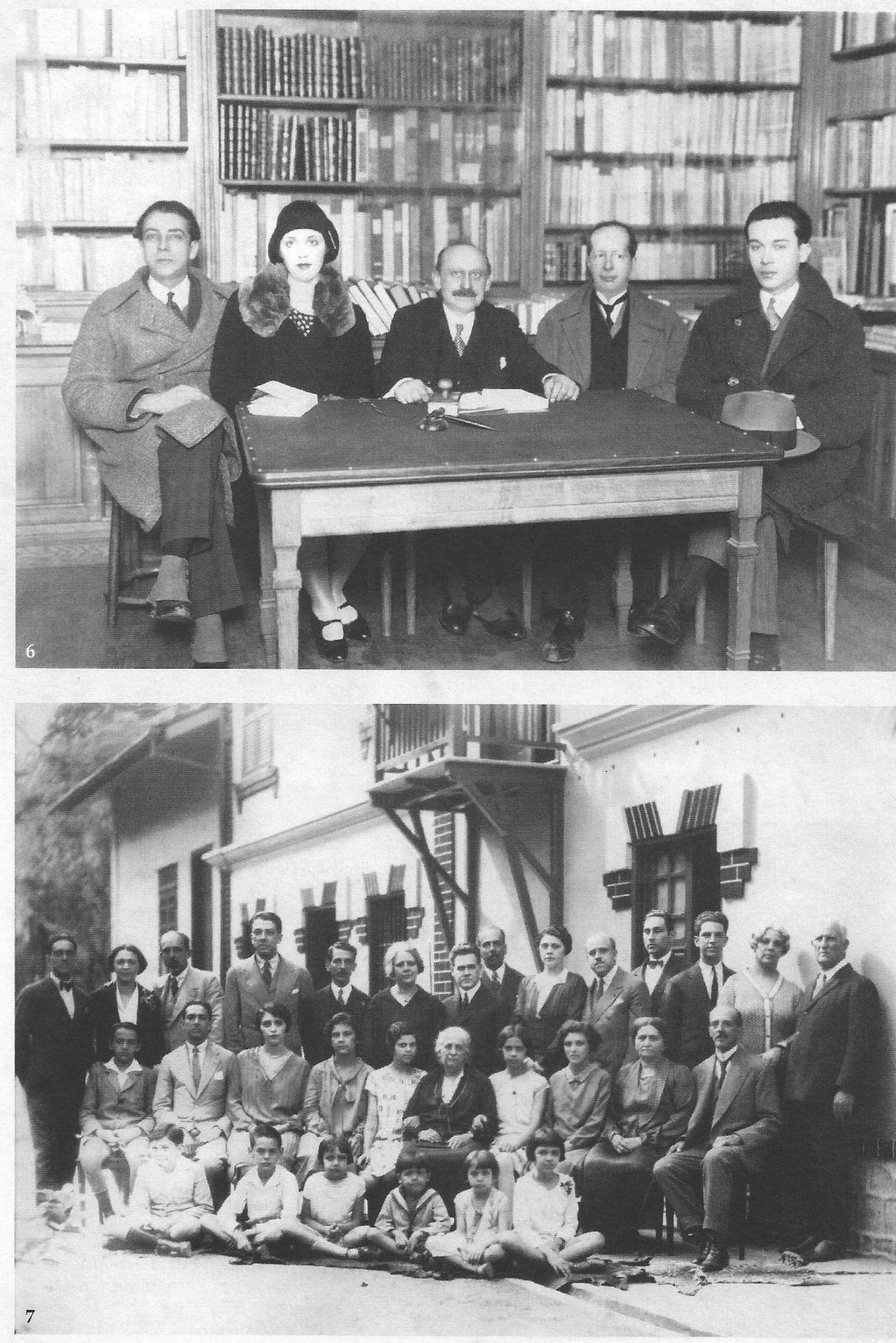

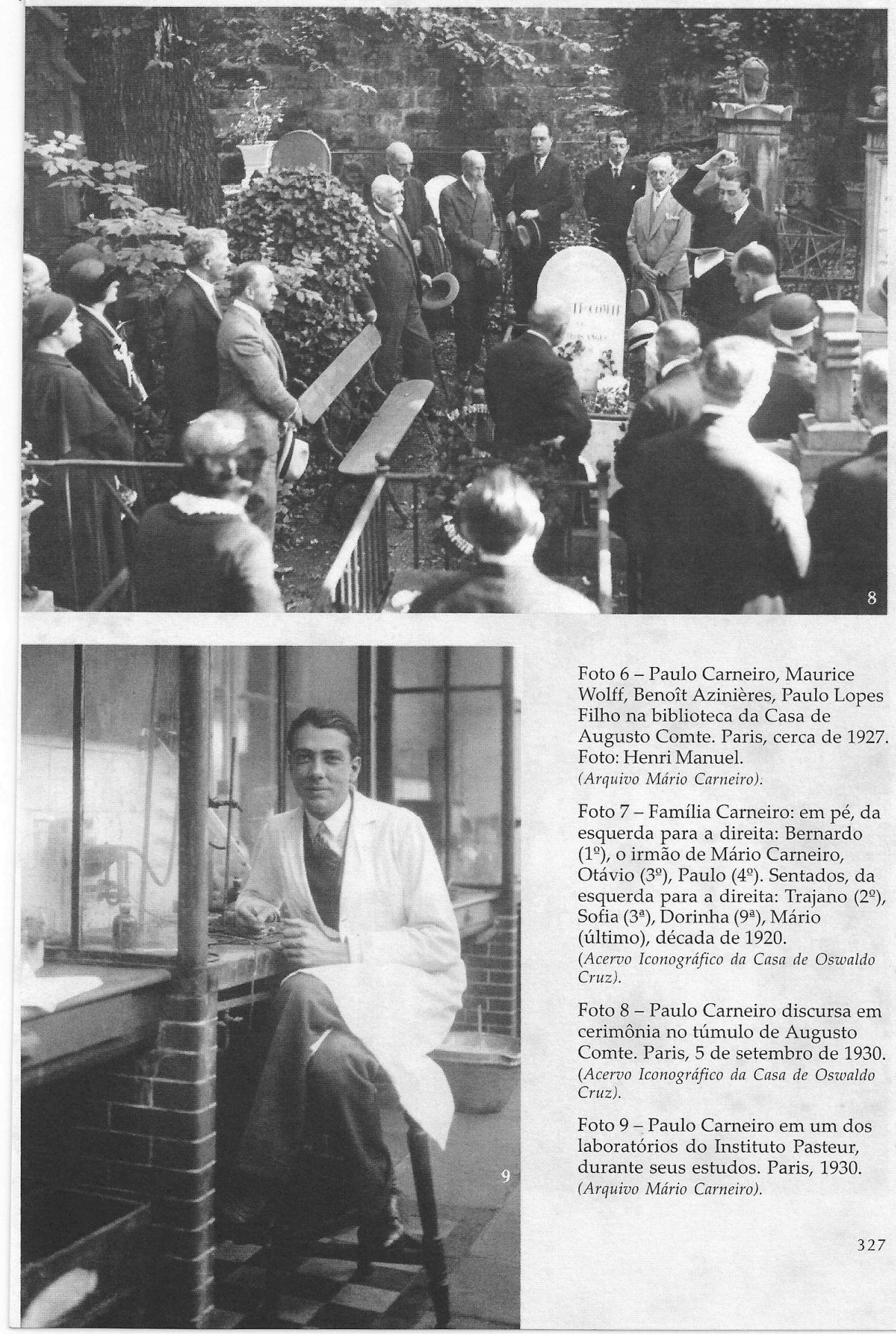

Foto 6 - Paulo Carneiro, Maurice

Wolff, Benoît Azinières, Paulo Lopes Filho na biblioteca da Casa de

Augusto Comte. Paris, cerca de 1927.

Foto: Henri Manuel.

(Arquivo Mário Carneiro)

Foto 7 - Família Carneiro: em pé, da esquerda para a direita: Bernardo $\left(1^{\circ}\right)$, o irmão de Mário Carneiro,

Otávio $\left(3^{\circ}\right)$, Paulo $\left(4^{\circ}\right)$. Sentados, da esquerda para a direita: Trajano $\left(2^{\circ}\right)$, Sofia $\left(3^{\mathrm{a}}\right)$, Dorinha $\left(9^{\mathrm{a}}\right)$, Mário

(último), década de 1920.

(Acervo Iconográfico da Casa de Oswaldo Cruz).

Foto 8 - Paulo Carneiro discursa em cerimônia no túmulo de Augusto Comte. Paris, 5 de setembro de 1930. (Acervo Iconográfico da Casa de Oswaldo Cruz).

Foto 9 - Paulo Carneiro em um dos laboratórios do Instituto Pasteur, durante seus estudos. Paris, 1930. (Arquivo Mário Carneiro). 


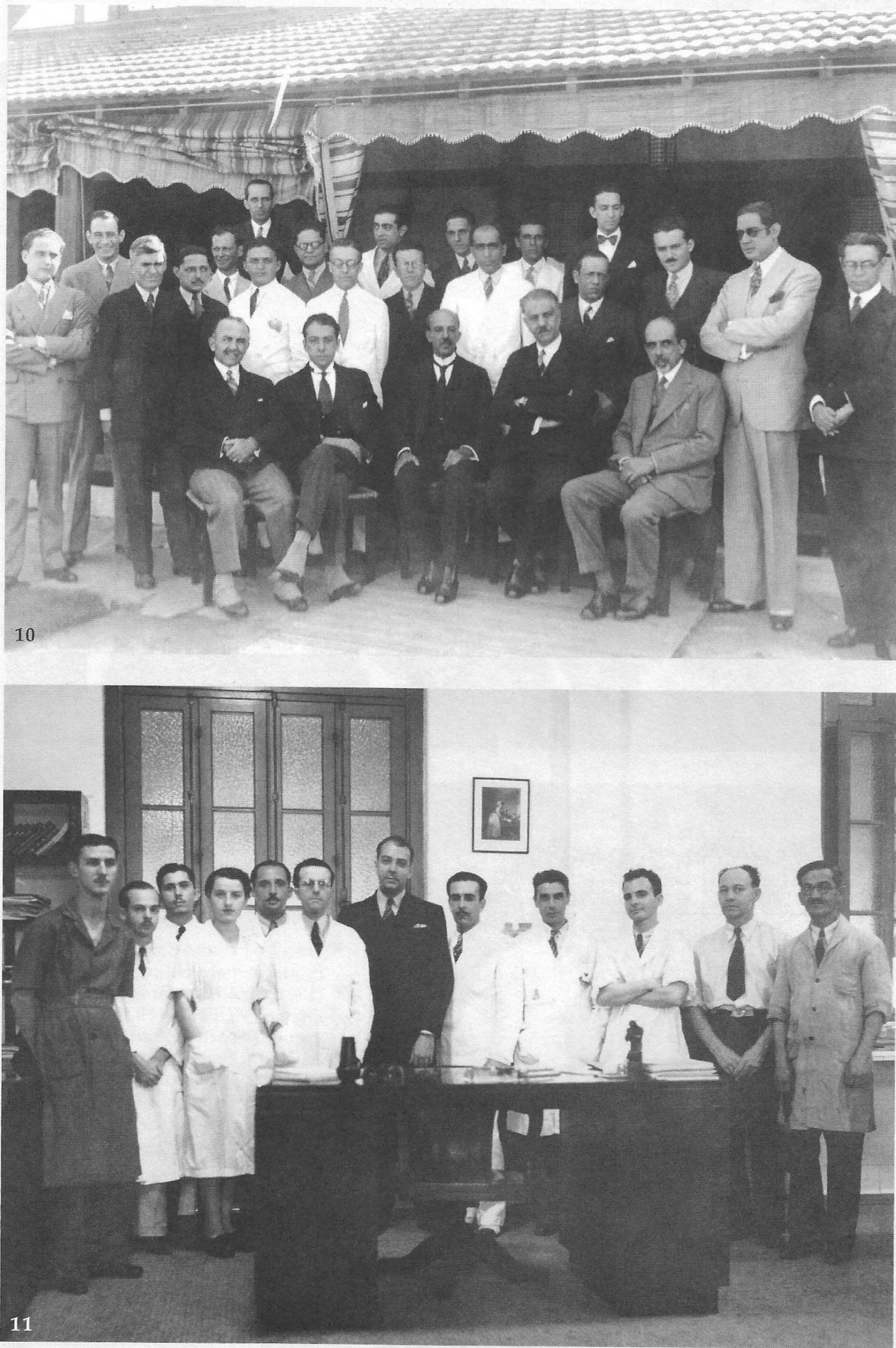



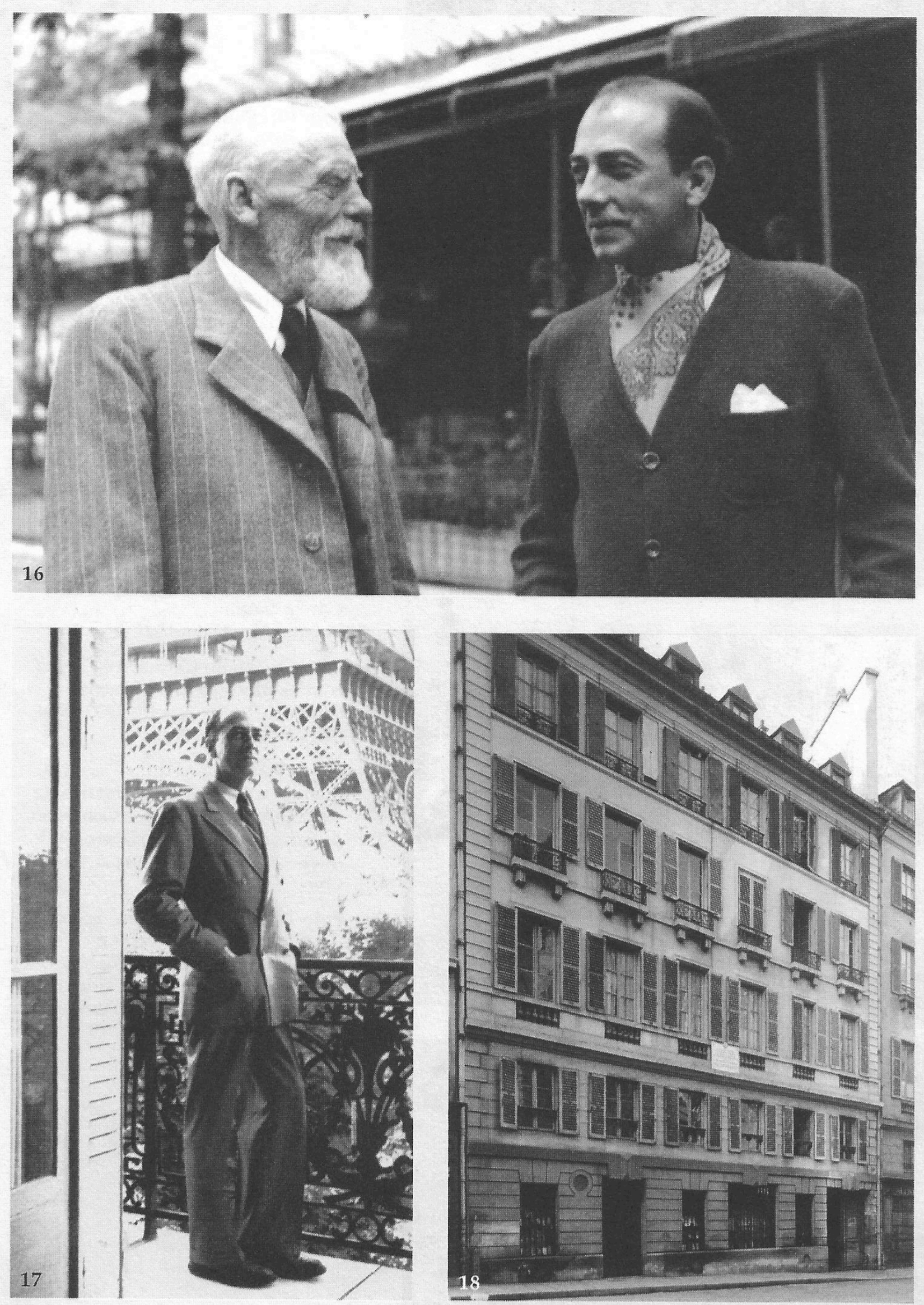

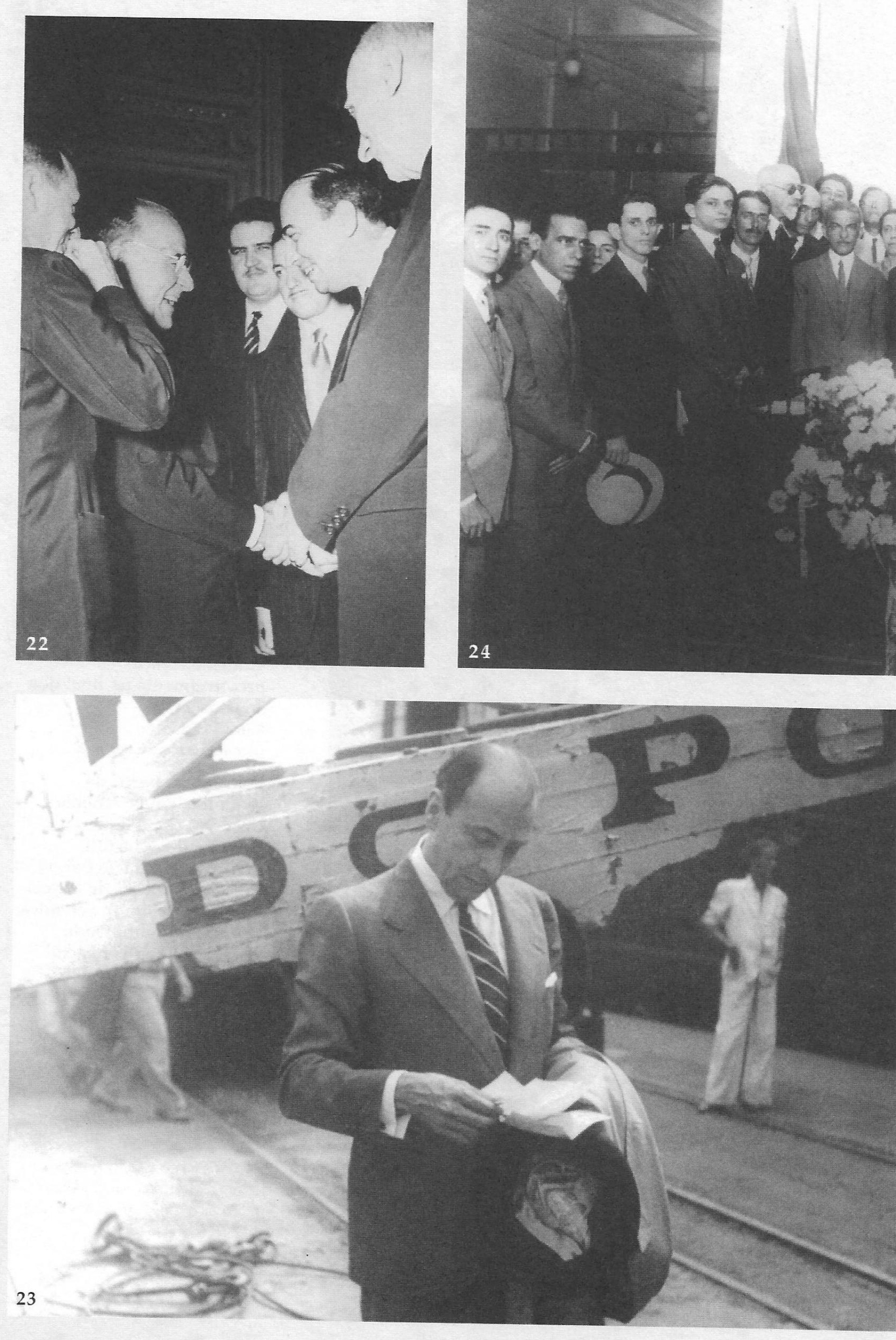


\section{DI}

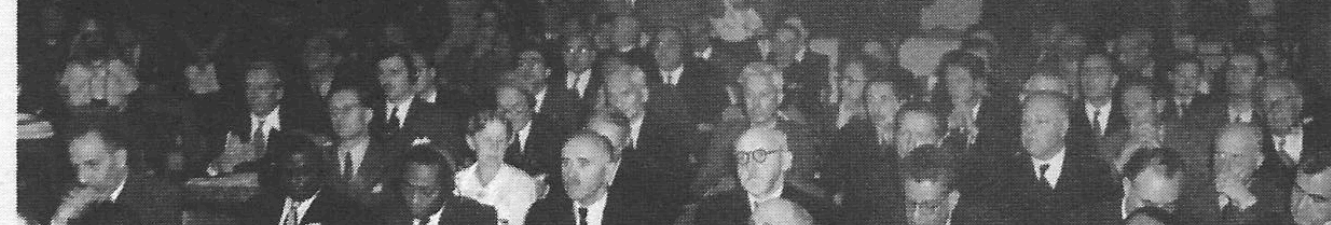

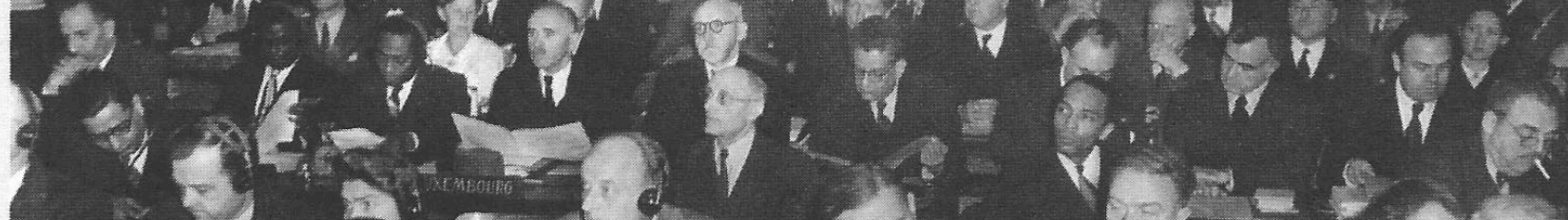

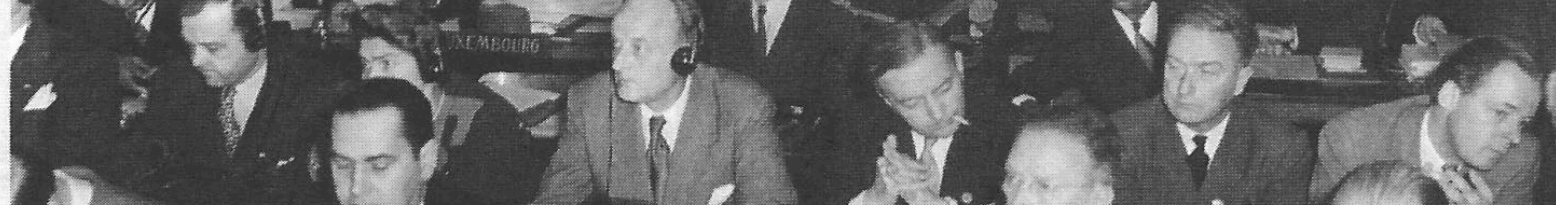
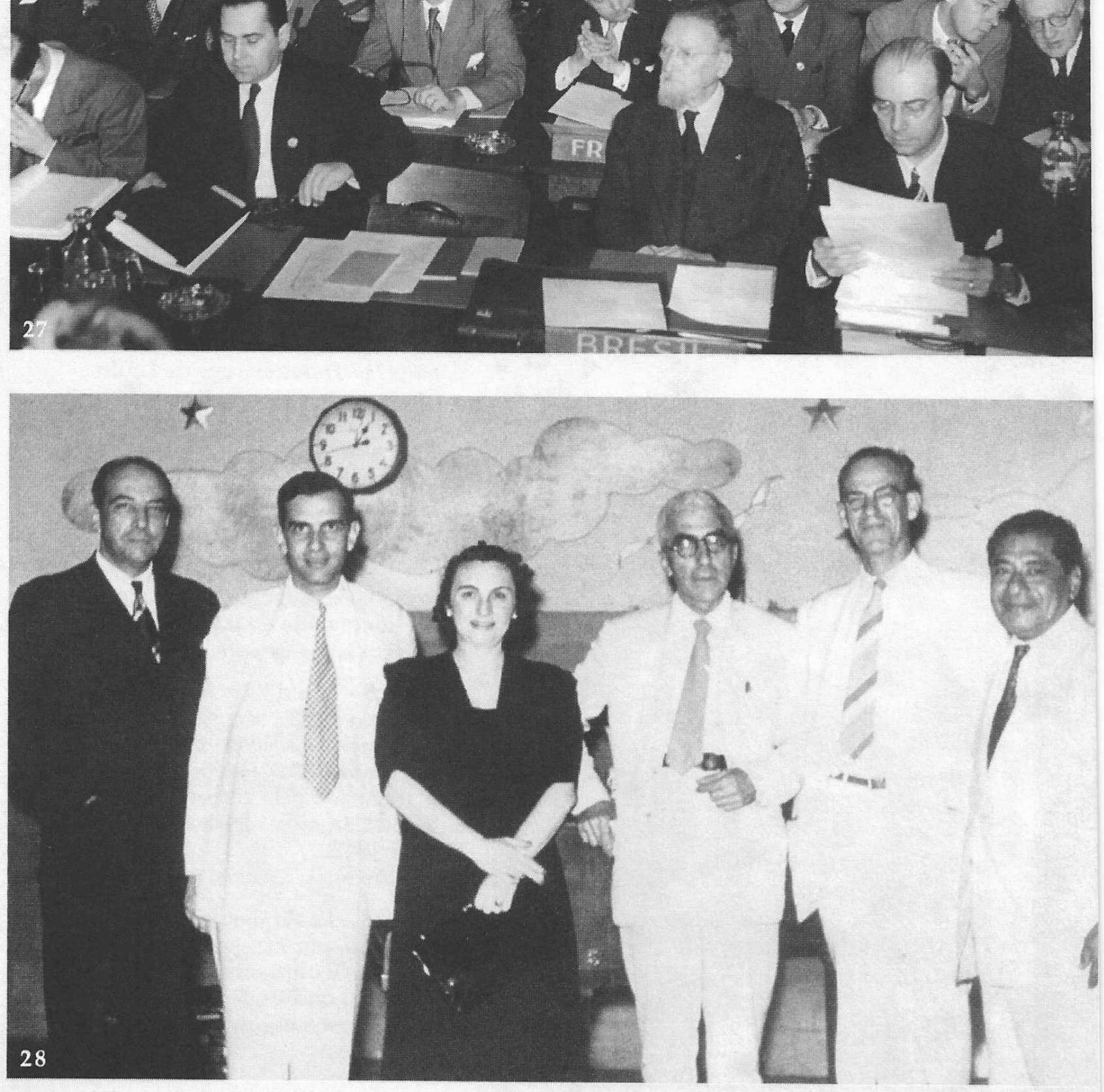

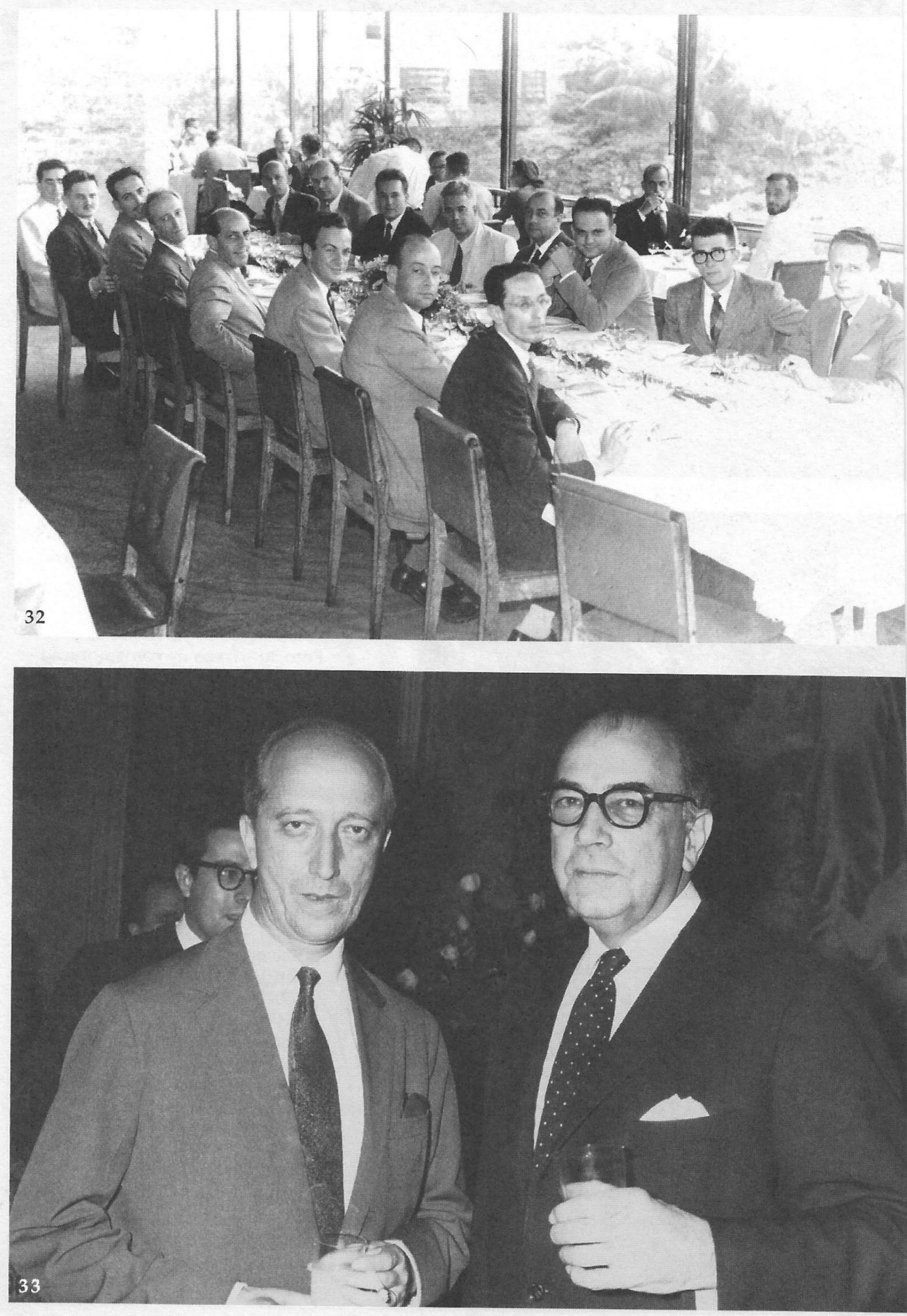

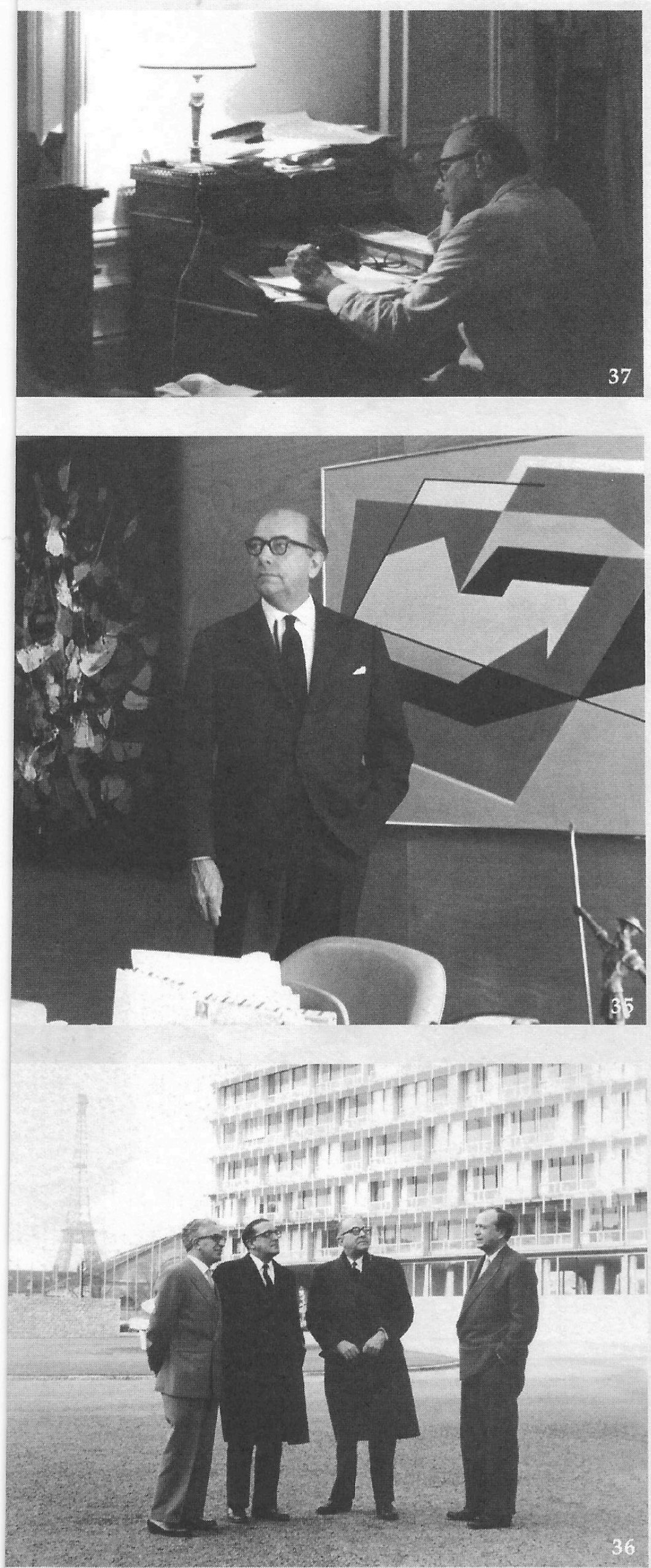

Foto 32 - Paulo Carneiro durante almoço em sua homenagem e em homenagem a Richard Feynman e Marcel Schein, do Centro Brasileiro de Pesquisas Físicas, no restaurante do aeroporto Santos Dumont. Presentes, da direita para a esquerda, na segunda fila, Paulo de Góes $\left(1^{\circ}\right)$, Ugo Camerini $\left(2^{\circ}\right)$, Cesar Lattes $\left(3^{\circ}\right)$, Paulo Carneiro $\left(4^{\circ}\right)$, Joaquim Costa Ribeiro (5), Nelson Lins de Barros $\left(6^{\circ}\right)$, Helmut Schartz $\left(7^{\circ}\right)$ e Gerard Hepp ( $\left.8^{\circ}\right)$. Na primeira fila, Gabriel Fialho

$\left(2^{\circ}\right)$, Richard Feynman $\left(3^{\circ}\right)$, Marcel Schein $\left(4^{\circ}\right)$, José Leite Lopes $\left(5^{\circ}\right)$, Hervásio de Carvalho $\left(6^{\circ}\right)$, Leopoldo Nachbin $\left(7^{\circ}\right)$ e Mauricio Mattos Peixoto $\left(8^{\circ}\right)$, cerca de 1953.

(Arquivo Mário Carneiro).

Foto 33 - José Leite Lopes e Paulo Carneiro em solenidade promovida pela Unesco.

Paris, 1953-1954.

(Acervo Iconográfico da Casa de Oswaldo Cruz).

Foto 34 - Paulo Carneiro em Londres, 1957-1958.

Foto: Mário Carneiro

(Arquivo Mário Carneiro).

Foto 35 - Paulo Carneiro em seu gabinete de trabalho na Unesco, entre pinturas de Cícero Dias e Antônio Bandeira, 1959.

Foto: Unesco.

(Arquivo Mário Carneiro).

Foto 36 - Carlos Lacerda (o segundo, a partir da esquerda), Paulo Carneiro e o arquiteto Zerfhuss, um dos responsáveis pela construção do prédio da Unesco em Paris, 1960.

Foto: Unesco

(Arquivo Mário Carneiro). 


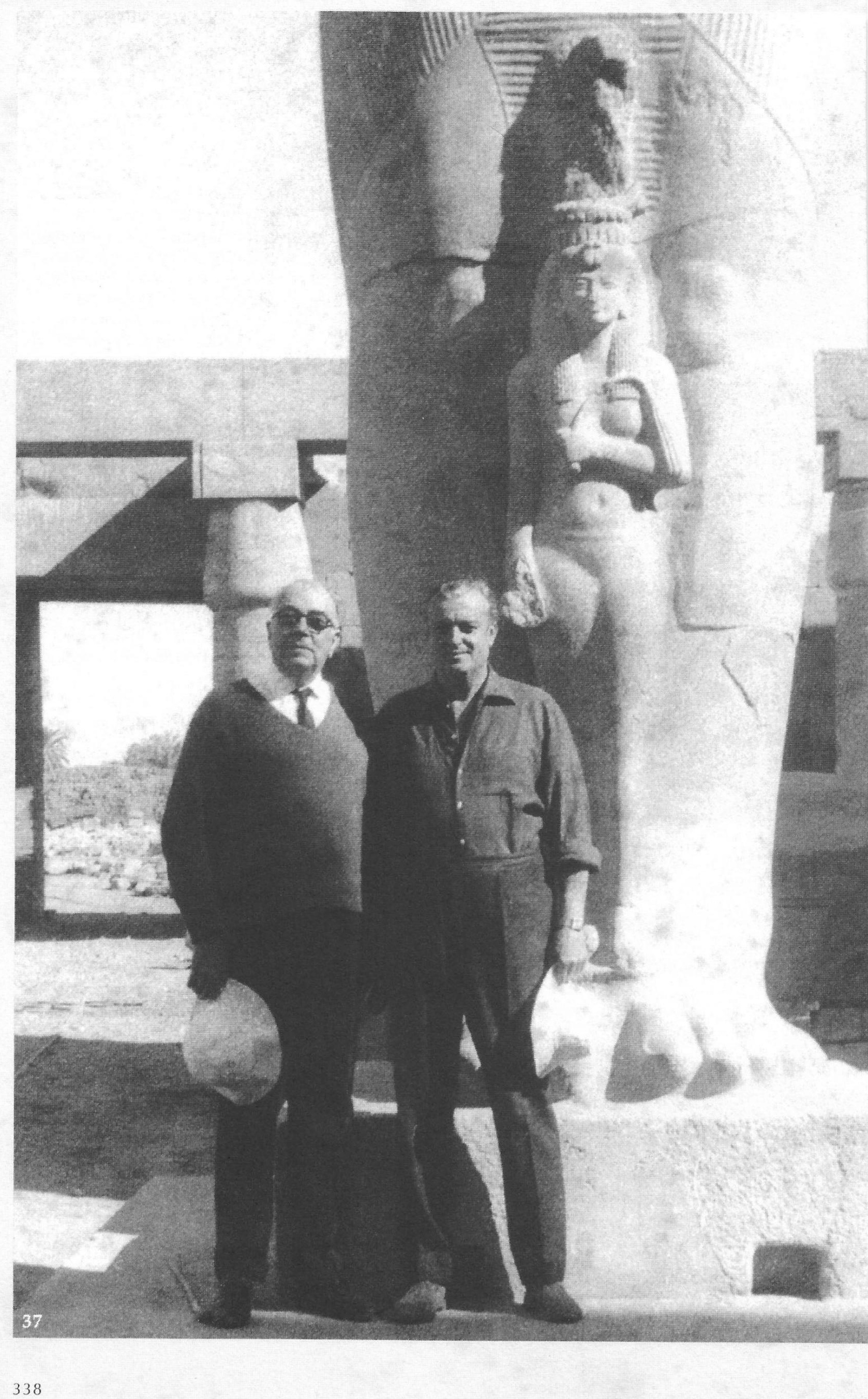



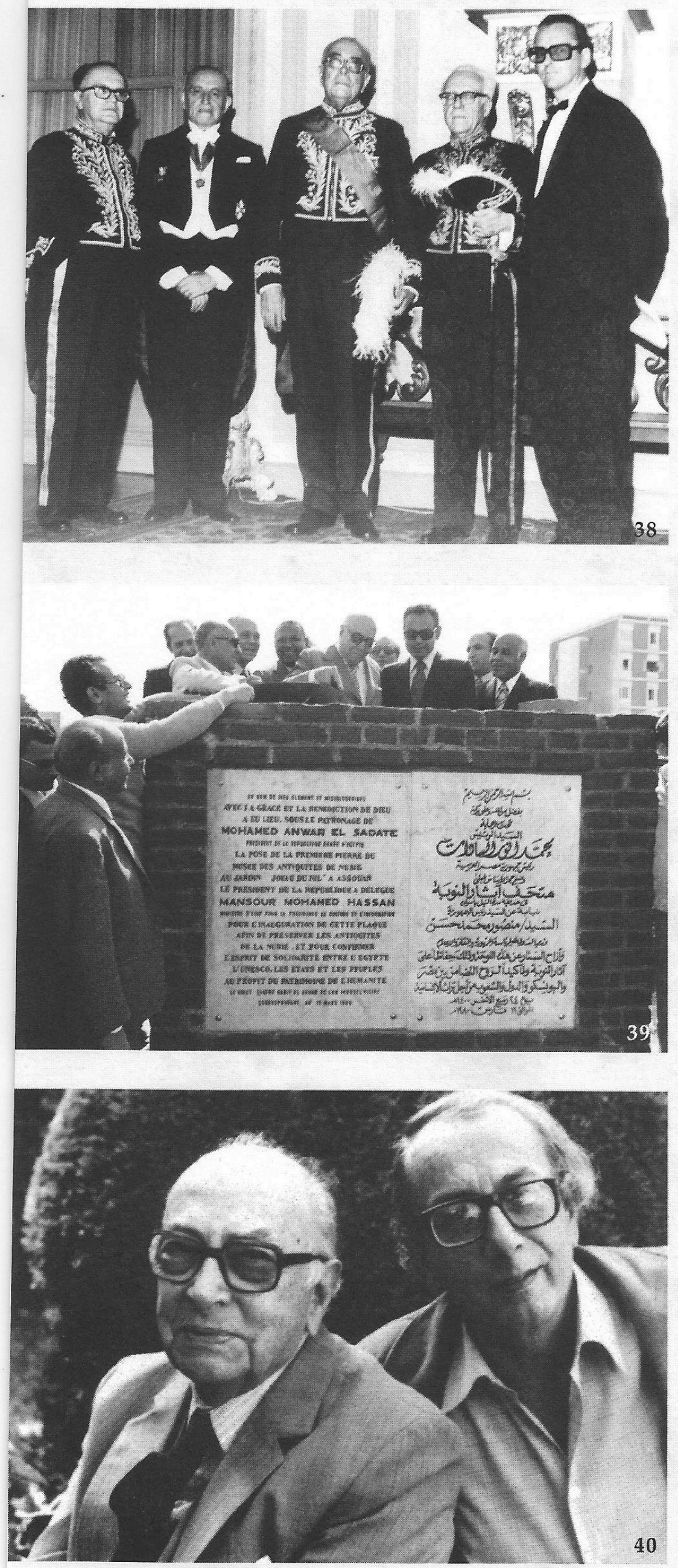

Foto 37 - Paulo Carneiro com o embaixador Roberto Assumpção. Egito, década de 1970.

(Arquivo Mário Carneiro).

Foto 38 - Paulo Carneiro na Academia Brasileira de Letras, com Hermes Lima (o $1^{\circ}$, da esquerda) e Ivan Lins $\left(\mathrm{o} 4^{\circ}\right), 20$ de maio de 1971.

(Acervo Iconográfico da Casa de Oswaldo Cruz).

Foto 39 - Cerimônia de lançamento da pedra fundamental do Museu de Antigüidades da Núbia, no Jardim Joyau du Nil. Presente, Paulo Carneiro, presidente do comitê executivo para a salvaguarda dos monumentos da Núbia, região situada ao sul do Egito, 11 de março de 1980. Foto: Unesco.

(Acervo Iconográfico da Casa de Oswaldo Cruz).

Foto 40 - Paulo Carneiro com seu filho Mário, em Paris, 1980.

(Arquivo Mário Carneiro). 
Formato: $16 \times 23 \mathrm{~cm}$

Tipologia: Palatino Linotype (miolo)

Palatino Linotype e Franklin Gothic Condensed (capa)

Papel: Print Max $90 \mathrm{~g} / \mathrm{m}^{2}$ (miolo)

Cartão Supremo $250 \mathrm{~g} / \mathrm{m}^{2}$ (capa)

Fotolitos: Graftipo Gráfica e Editora Ltda. (capa)

Impressão e acabamento: Imprinta Gráfica e Editora Ltda.

Rio de Janeiro, outubro de 2004.

Não encontrando nossos títulos em livrarias, contactar a Editora Fiocruz:

Av Brasil, 4036 - 1aar a - sala 112 - Manguinhos

21041-361 - Rio de Janeiro - RJ

Tel.: (21) 3882-9039 e 3882-9041

Telefax: (21) 3882-9006

e-mail: editora@fiocruz.br

http://www.fiocruz.br/editora 